\section{ICMC 2008 Reviews}

Sonic Arts Research Centre, Queen's University, Belfast, Northern Ireland

\section{ICMC 2008 Review}

\section{by Kazuaki Shiota}

I am a composer, and often create music with my algorithmic sound system, \{TranSpell $\}$. I have been continuously giving a demonstration of $\{$ TranSpell $\}$ as well as performing my music at the ICMC since 2006. Recently, I started incorporating movement into $\{$ TranSpell $\}$, so I became interested in how to integrate between sound and motion.

ICMC 2008 was the first time I saw the mobile phone orchestra composed by Georg Essl, Henri Penttinen and Ge Wang. The title was MoPhO: Suite for Mobile Phone Orchestra, and the performance assured the ability of mobile phones for live electronics and removed the borderline between computer music and mundane life. It was visually interesting and beautiful when the performers moved their hands up and down to transform data.
I was fascinated by the aesthetic performance of The Color of Waiting, composed by Margaret Schedel and choreographed by Alison Rootberg. The dancer was holding two light sensors to control the watery sound in real-time. The three blind curtains were hung from the ceiling to be projected upon with the images of eyes and waves. The dancer was not entirely seen in the performance. Most of the time, she was moving across the domain of shadow and light. Thus, the music was well integrated with the motion. Personally, I collaborate with a modern dancer, so the work enlightened me to the practical path to create collaborative works. I am looking forward to seeing further progress on the integrity between sound and motion at the upcoming ICMC 2009 at McGill University.

Kazuaki Shiota

DMA student at University of Cincinnati College-Conservatory of Music Lecturer at Shobi University in Japan

\section{A Life-changing Experience: My Personal Account of ICMG 2008}

by Rsbrand Otjes

This story begins with me trying to get back in to my field. After graduation, I fell into a black hole of some sort. I got 
a job at a call center and didn't have any contact with anyone from my former college. I didn't like my job and had no use for the knowledge I learned over the course of 4 years being a student at the HKU (Utrecht School of Arts). I contacted a couple of my former fellow students to no avail. Most of them weren't interested in getting back into contact with me, with the exception of Toine. He told me there was a concert of secondyear HKU students, and in an act of spontaneity I went. There I met up with him and a former teacher called Hans. They told me about the ICMC and invited me to come along. Toine told me it was going to be at least an experience that would keep me inspired for a year, and at most a life-changing experience. Time slipped by, and the plan nested itself somewhere in the back of my head while I got on with life. After a couple of months I casually contacted Toine to poll if the plan was still standing, only to find that he already planned the whole thing, and if I wanted to come with them I should get on with it, so I did. In one week I got free from work, registered and paid for a ticket for the ICMC, reserved a bed at the same hostel Toine was staying, and booked myself a flight. Two weeks later, I got on the plane, flew to Ireland and landed the same day the ICMC was set to begin.

The first thing I noticed when I arrived in Ireland was that my cell phone didn't work anymore. I could receive calls and texts, but when I tried making calls, I constantly heard, "This number is barred from your phone." Luckily, I had written down the street my hostel was on. So after asking around and going on a slight detour, I arrived at my hostel. However, there was nobody to check me in. I dropped my bags in their laundry room and I decided to get registered at Queen's University, which I had seen earlier when looking around for the hostel. It was a majestic looking castle, and the insides where beautifully groomed. I followed the signs and saw the registration desk. After telling them my name, I got a big bag full of goodies and even the T-shirt that I paid for in advance. Later that week I noticed it even had my name on it - how cool!

I felt a little scared in this huge city in another country and I was proud that I had gotten this far, but I felt it was time to meet up with Toine. I got a text from him, but couldn't text him back. It said that he was already at the university and couldn't meet up with me. I had some unfinished business at the hostel, so after registration I headed back to the hostel. There, I met up with some other students from the HKU and had some dinner.

After having eaten, we went to our first concert session. There I expected some electronic sound exploration, but instead 
I got treated with some "electro-acoustic" music, which I didn't really like that much. I thought Colin Johnson's work called It's All Out There on the Internet was a very funny and novel idea, but I left the hall with a distinct impression that maybe this wasn't my thing and that it had been a bad idea to go to the ICMC after all. I overreacted, I know, but you have to remember that I was on a bit of an emotional roller coaster - the flying, the huge city, the new social group, the awesome beauty of the university building and then the weird music to which I was not accustomed anymore. It was a bit too much for this poor boy.

The next morning, I went to my first of lecture of the week. It was about sound synthesis. The first topic was "split-sideband synthesis," which was certainly a very interesting concept but wasn't the life-changing lecture I thought it would be. This would continue on. I either didn't understand what they were doing or I couldn't understand the major revolution that their ideas and research would bring to their specific field. My streak of insecurity ended when I visited the Sonic Lab, which is a beautiful room inside the SARC building. Siebe and I were a little bit late for the concert, but we were fortunate enough to sneak in after the second piece, and then I heard a very good piece: Friction by Jason Bolte. There were snippets of real world sounds floating above you and all around you in this beautifully dimly lit room. But what I really loved was how these sounds were locked up through what I felt to be the sounds of doors shutting above you. It took me on a very interesting ride, and because the room was pretty dark, none of my other senses could get a hold of my thought process and I got to really enjoy only the surround sounds.

This experience really helped to get my negative feelings about being there in context. At first, I hadn't understood that I was allowed to dislike stuff here. I thought it was all supposed to be light-years ahead of what I learned or experienced at my college. I thought I simply wasn't tuned in to it, or maybe even too dumb to understand what I was hearing. But that simply wasn't the case. They were exactly doing what I was doing at the HKU - research. This wasn't school, it was a community of computer music aficionados and sound/music scholars, and they were just presenting these papers so that others might benefit and build upon their work.

By the time we went to the Black Box that evening to watch an informal live coding event, the negative feelings were reduced to a distant memory. I felt I really connected with the Dutch group I was with, and I really enjoyed the live coding - all of it, from the glitchy 
nastiness of Yee-King and the soothing automation of Graham Coleman to the Max/MSP improvisation by our very own Luc van Weelden.

The next day, I looked around the university terrain and went with a couple of the guys to the Sonic Lab. There I heard a wonderful piece. It had surprise, it was immediate, and it was precisely long enough for its intention. It was Exit Variation 2 by Roger Doyle. As with the all of the concerts, we were handed the program, and one of the pieces had a really interesting title: Radiant Telemetries: Musical Settings of Celestial Images from the new General Catalog I: NGC2023 (Horse Head Nebula). Recently I've taken an interest in what kind of sounds we can hear from space (it being a vacuum and all) and maybe data converted to a wave of some sort. However, we were treated with very poorly executed video effects and a very uninspired piece of music. Lamentation Alphabet: Aleph by Benjamin Broening, however, was a very good piece that really utilized the surround system. It sounded warm and organic while still maintaining that technological sub-layer in its sound.

After that, we went to the "Re-inventing audio and music computation for manycore processors" panel, which was very interesting but not really up my alley, because I'm not much of a programmer. However, it was very interesting to discover that the audio/music community is also debating about what to do next and how they can benefit from the change to multi-core processing because of the limit of Moore's law.

The evening again brought us a lot of performances. The one that stood out for me was by Juhani Räisänen and was called Cringle, which was an audiovisual piece. Both audio and video were generated live: the sound was synthesized, and the visuals from a camera pointed in his direction were processed in real time. Both the synthesis and the video processing were controlled by this lightsaber-like wireless instrument in his hands, with which he was dancing in front of the camera. It was awe-inspiring, although I have to admit that I liked the visuals better than the music.

Later that night we went to see the performances in Mandela Hall, where the most informal of the performance sessions were held each day. There was music in one room, where you could casually walk in and out, and a bar on the other side, where you could chill. I sat down in the performance room, and noticed all of these radios above our heads. They were for a piece by Anna Friz entitled Radio is Everywhere in Their Dreams. It is quite a long piece - 30 minutes - and I didn't have the patience to sit down for that time. I have the distinct impression that it wasn't 
made for sitting down. Whatever may be the case, I did like it. I enjoyed the use of voices, and the text you hear them say. It projected a beautiful atmosphere of calm and loneliness. Next Matthew Yee-King performed, without a beamer displaying his programming. Too bad - it made it that much more interesting when I saw it the day before, but it wasn't a bad performance by any standard.

On the 28th I attended the Sonic Lab concert, but nothing piqued my interest. The demo sessions were next. We went to the presentation of "Two Network Installations: '1133' \& 'Computer_ Voices" by Vincent Akkermans and Than van Nispen tot Pannerden, two other guys from the Dutch delegation. There I got a chance to see what my old school is up to these days. I found the performances interesting and very interactive, because I really felt the urge to join in.

At the poster presentations, I got a chance to talk to Juhani Räisänen. I got to see, hold and even play his Sormina, the wireless object I described earlier as being like a lightsaber. The Sormina is a really interesting instrument, but the philosophy behind what Juhani is trying to accomplish is even more captivating. He wants his instrument to be devoid of radical changes. This gives performers a chance to really learn to be fluent with it. It gives pieces of music a chance to develop, and it takes the Sormina out of the realm of controllers and into the realm of a real instrument. That is evident in the choice to use wooden knobs on the potmeters and the decorative wooden neckpiece. I also spoke with Enda Bates about his paper "Adapting Polyphonic Pickup Technology For Spatial Music Performance." He explains how to get 6 separated signals - one for each of the strings - out of an electric guitar, and shows his idea to use it in a surround sound performance. It really opens up possibilities, because of the greater control you have over your signal path.

In the meantime, my group was buzzing with excitement for the performance of the Electronic Hammer later that evening. There were three performances, one composed by Henry Vega called Izumi, one by Rodrigo Sigal called $M e(n) T A L$ and Music for Snare Drum and Computer by Cort Lippe. I did like the use of the metallic stool, but the performance as a whole just didn't work for me. The rest of the Dutch group, however, really liked it, and even found the 10 minutes of finding every method of beating on a snare drum fantastic. I can't dispute the fact that the performer is really skilled, but 10 minutes of snare drum is a bit too much for me.

Then some weird gray-haired man walked on stage, took a seat behind an array of bells and cymbals, crouched down, and 
fumbled with his hands in his suitcase, only to arise with a thimble on each finger. He started playing the bells as if they were sacred, and treated his daf in a similar fashion, needing to stroke it before playing. The piece was complemented with tastefully placed, but more importantly, musically pleasing electronic sounds. The text really seemed to fit as well, finding the music, and the music finding it. I loved the whole performance; the build-up and the climax were beautiful. It was a piece by Alessandro Cipriani called Bi Ma (Devoid of Self), performed majestically by Mahammad Ghavi Helm, who also performed Altri Passaggi by Fabio Cifariello Ciardi.

By this time I felt really at ease. I knew what I liked and what I didn't like. In short, I got to know myself, but I got to know a lot of people there as well. I noticed I could just go up to a person, introduce myself and talk about stuff. Everybody earned instant respect from everybody else. I knew that this is where I belonged. I had new hope for my personal future and I vowed then and there that I would be at the next ICMC.

The last day of the ICMC, I went on a small mission to get my hands on all of the Exit Variations. They were perhaps the best things I heard at the ICMC, because of their small durations, their innocence and the joy with which I anticipated them every concert. I finally got the info that they would be placed on the website in due time, and that I would be able to download them to listen to them on my MP3 Player.

I also attended my last lecture session of the ICMC, "Algorithmic Composition Tools 3." Here I learned about "The Bigbang Rubette: Gestural Music Composition With Rubato Composer" by Florian Thalmann and Guerino Mazzola. It looked like a really nice method of composing music, and I asked them to contact me when it would be available so I could compose with it.

Then it was the last evening of concerts. It included, of course, the final Exit Variation. Also of note was Oboe_prosthesis by Michael Young, where Chris Redgate, through his oboe, engaged a neural network, which in turn engaged the improviser. The piece was fascinating to listen to, and I noticed that I could understand what was happening here-something I knew I couldn't have done at the beginning of the ICMC. Georg Hajdu's Ivresse '84, with the European Bridges Ensemble and violin by János Négyesy, got an enormous response by the crowd there, including me. It tells the story of an incident that happened in Ivrea in 1984, taken from an interview with the very same János Négyesy. The piece was accompanied by a beamer displaying the actual text and the parts 
played by the performers.

In conclusion, my good friend Toine was right. The ICMC was certainly an inspiration for me, and only time will tell if it was a life-changing experience. Now I know where I belong, and I will do everything in my power to stay there. 